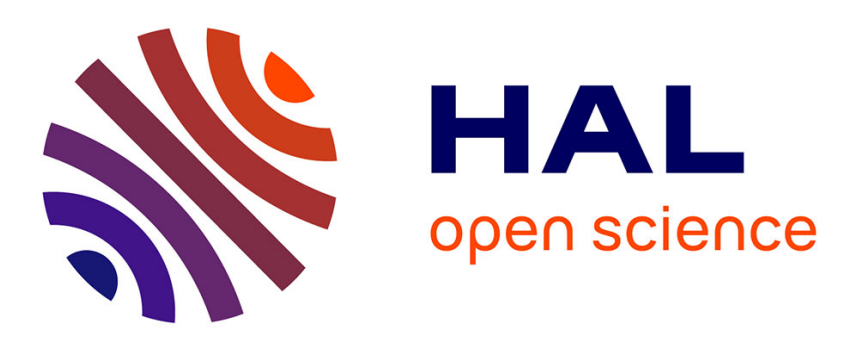

\title{
Formation of CVD copper films investigated by surface analysis and reflectivity
}

Z. Hammadi, B. Lecohier, A. Cros, H. Dallaporta

\section{To cite this version:}

Z. Hammadi, B. Lecohier, A. Cros, H. Dallaporta. Formation of CVD copper films investigated by surface analysis and reflectivity. Journal de Physique IV Proceedings, 1993, 03 (C3), pp.C3-91-C3-98. 10.1051/jp4:1993311 . jpa-00251368

\section{HAL Id: jpa-00251368 https://hal.science/jpa-00251368}

Submitted on 1 Jan 1993

HAL is a multi-disciplinary open access archive for the deposit and dissemination of scientific research documents, whether they are published or not. The documents may come from teaching and research institutions in France or abroad, or from public or private research centers.
L'archive ouverte pluridisciplinaire HAL, est destinée au dépôt et à la diffusion de documents scientifiques de niveau recherche, publiés ou non, émanant des établissements d'enseignement et de recherche français ou étrangers, des laboratoires publics ou privés. 


\title{
Formation of CVD copper films investigated by surface analysis and reflectivity
}

\author{
Z. HAMMADI, B. LECOHIER, A. CROS and H. DALLAPORTA
}

GPEC URA-CNRS 783, Faculté des Sciences de Luminy, Case 901, 13288 Marseille cedex 9, France

\begin{abstract}
In this contribution we investigate the formation of copper films by chemical vapor deposition on silicon using the copper (II) bis(acetylacetonate) precursor. From Auger spectroscopy and ion sputtering, the chemical composition of the film is determined. We show that the carbon is on the CVD copper surface and plays an important role in stabilizing the silicon copper interface. The formation at $300^{\circ} \mathrm{C}$ of a metallic copper film on silicon instead of copper silicide is explained by the presence of carbon. The resistivity versus temperature has a behavior similar to the one observed on an evaporated copper film. Its value is for the best film two times higher than for pure copper. We present the evolution of the reflectivity of the film measured in situ during the MOCVD growth. Following the evolution of the reflectivity during the MOCVD process can give information on the nucleation process, the growth rate and the evolution of the roughness of the film.
\end{abstract}

\section{INTRODUCTION:}

Chemical vapor deposition using organometallic precursors is a powerful technique for the metallization in microelectronic applications. We have shown [1] [2] by XRD and Auger spectroscopy that for our deposition conditions, metallic copper is obtained even with oxygen in the gas phase on both (111) and (100) silicon substrates. To understand the formation of the copper film on silicon, we followed the growth by measuring the reflectivity during the deposition process and the composition of the deposit at different stages of the growth by Auger spectroscopy. These results are in contradiction with what is reported in the literature [3] when copper is 
deposited on clean silicon by physical evaporation. It is well-known that at $200^{\circ} \mathrm{C}$ copper reacts with silicon to lead to a copper rich silicide.

\section{EXPERIMENTAL SETUP AND PROCESS CONDITIONS}

The originality of the experimental set up comes from the capability of measuring the evolution of reflectivity during the CVD process and the Auger spectra without exposing the sample to the atmosphere. Both reactor and analysis chamber are UHV compatible where the base pressure is in the low $10^{-9}$ Torr range. Former papers [1] [2] describe the details of the experimental setup. The quasi normal $\left(10^{\circ}\right)$ reflectivity at $670 \mathrm{~nm}$ is measured during the process. The reflectivity increases from $36 \%$ to $90 \%$ when $80 \mathrm{~nm}$ copper film is deposited on silicon. In this case, the formation of a $5 \mathrm{~nm}$ layer can be easily detected during the CVD process. To allow the comparison between different deposition conditions and the ideal layer by layer growth, the measured value on bare silicon is taken as a reference at $36 \%$.

The results reported below are obtained on $\mathrm{Si}(111) .1 \Omega \mathrm{cm}$ wafer using acetylacetonate copper (II) as the precursor. Before loading in the CVD reactor, the sample is degreased in acetone followed by HF dip during $20 \mathrm{~s}$ at room temperature. Such chemical etching leaves the silicon surface oxide free. The main deposition parameters are listed in table $\mathrm{N}^{\circ} 1$. In this study, only the substrate temperature (Ts) has been varied.

\begin{tabular}{|l|l|l|l|}
\hline Pressure & Wall Temperature & Precursor Temperature & Oxygen Flux \\
\hline $10^{-1}$ Torr & $150^{\circ} \mathrm{C}$ & $140^{\circ} \mathrm{C}$ & $1 \mathrm{sccm}$ \\
\hline
\end{tabular}



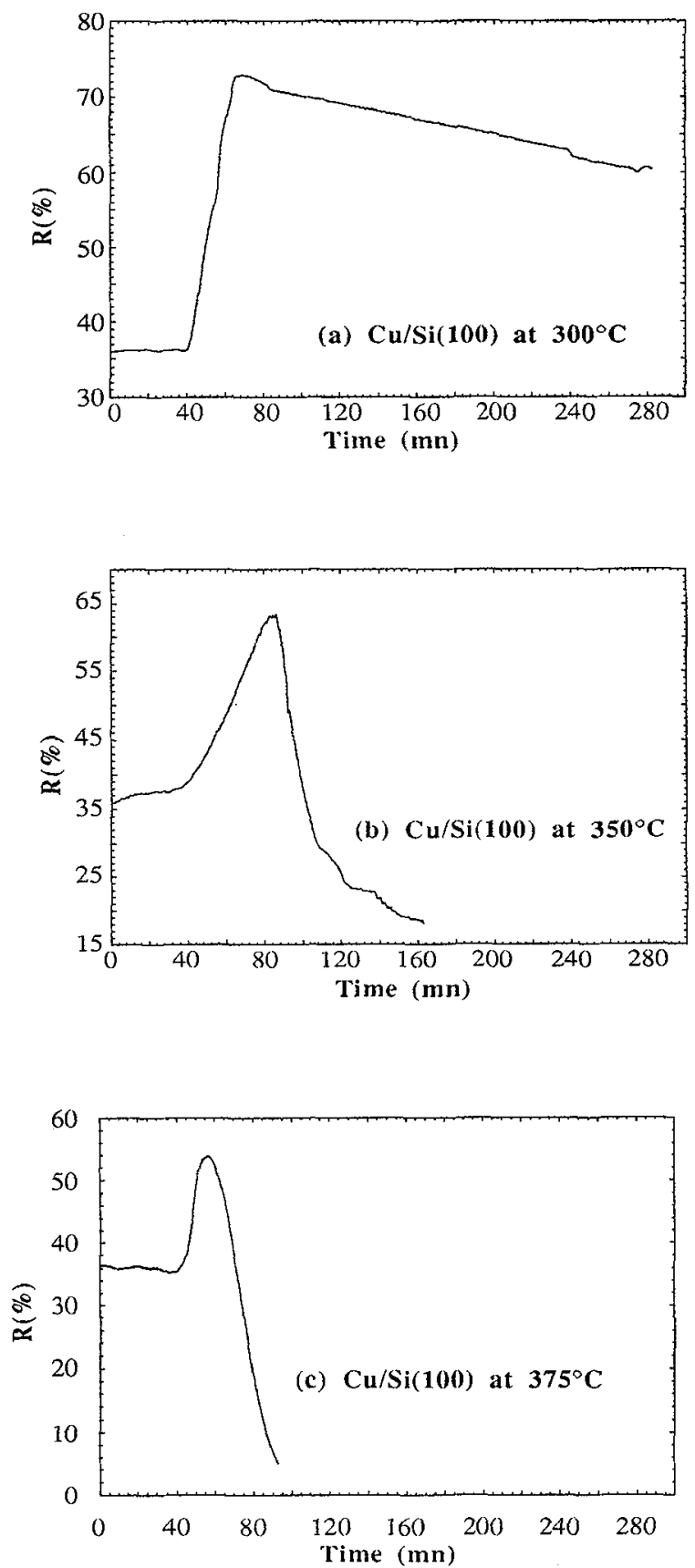

Fig. $\mathrm{N}^{\circ}$ 1: Evolution of the reflectivity during the CVD process for different temperatures. a) $300^{\circ} \mathrm{C}$, b) $350^{\circ} \mathrm{C}$ and c) $375^{\circ} \mathrm{C}$. 
EXPERIMENTAL RESULTS:

In figure $\mathrm{N}^{\circ} 1$, the evolution of the reflectivity versus time is presented for three different values of the substrate temperature $\left(300^{\circ} \mathrm{C}, 350^{\circ} \mathrm{C}, 375^{\circ} \mathrm{C}\right)$. The plots are shifted by the so call induction time [4][5] to get the change of the reflectivity at the same time for each value of the temperatures. The evolutions of the reflectivity are very different compared to what could be expected in the case of the ideal model where copper is supposed to grow layer by layer. The maximum is in all cases lower than the value obtained for an $80 \mathrm{~nm}$ thick flat copper film. After the maximum, the reflectivity decreases with a slop increasing with the temperature. Another difference, occurring only for deposition at $375^{\circ} \mathrm{C}$, is the decrease of the reflectivity after the induction time.

Samples were processed in the same deposition conditions (table $\mathrm{N}^{\circ} 1$; $\mathrm{Ts}=350^{\circ} \mathrm{C}$ ) but stopped at different stages of the reflectivity curve and analyzed by Auger spectroscopy.

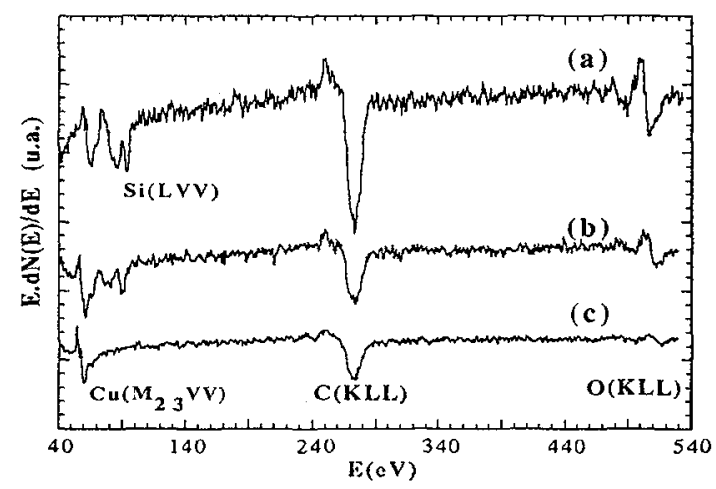

Fig $\mathrm{N}^{\circ}$ 2: Auger spectra of a CVD copper deposition at $350^{\circ} \mathrm{C}$ on silicon at different values of the reflectivity. a) $39 \%$, b) $50 \%$, and c) $62 \%$

The figure $\mathrm{N}^{\circ} 2$ gives the Auger spectra obtained on such samples where a),b) and $\mathrm{c}$ ) correspond to samples stopped when the reflectivity reaches $39 \%, 50 \%$ and at the maximum respectively. On spectrum a) (fig. $\mathrm{N}^{\circ} 2$ ), the main peak is around $272 \mathrm{eV}$ corresponding to carbon. At low energy the complex structure is composed of the copper $\mathrm{M}_{23} \mathrm{VV}$ Auger transition around $58 \mathrm{eV}$, the silicon LVV Auger transition at $92 \mathrm{eV}$ and in between a structure due to silicon oxide since oxygen is detected at $516 \mathrm{eV}$. In spectrum b), one can retrieve the same transitions as in a) but with a change in the relative intensity. Copper 
transition at $58 \mathrm{eV}$ has the same intensity compared to the one on the spectrum a) but all others are lower. Finally on c), at low energy only the complex structure has disappeared leaving the double copper transition, while high energy Auger lines are less intense compared to a) or b).

The figure $\mathrm{N}^{\circ} 3$ is the SEM picture of a sample obtained at the deposition conditions given above for a substrate temperature of $300^{\circ} \mathrm{C}$. One can see

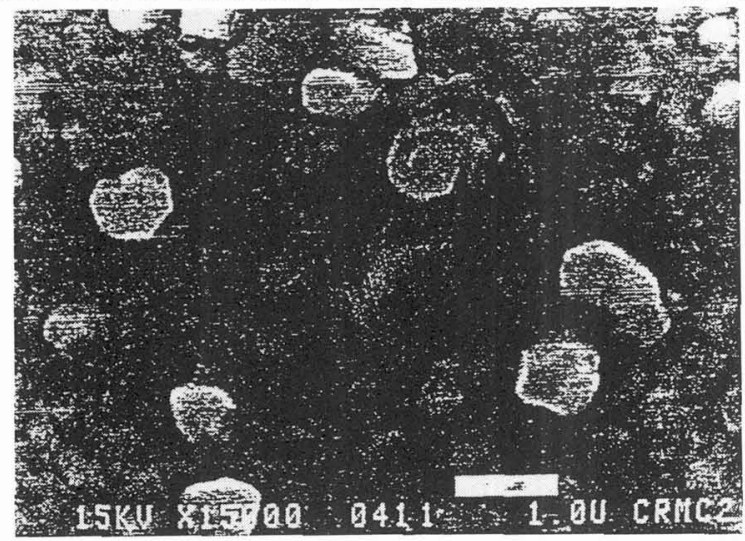

Fig $\mathrm{N}^{\circ}$ 3: SEM picture of a CVD copper film grown at $300^{\circ} \mathrm{C}$.

that the film consists of crystallites of $0.6 \mu \mathrm{m}$ in diameter with hexagonal shape.

The resistivities at room temperature and the variations of the resistance versus temperature are given in figure $\mathrm{N}^{\circ} 4$ for a $300^{\circ} \mathrm{C}$ CVD copper film and a physical evaporated one.

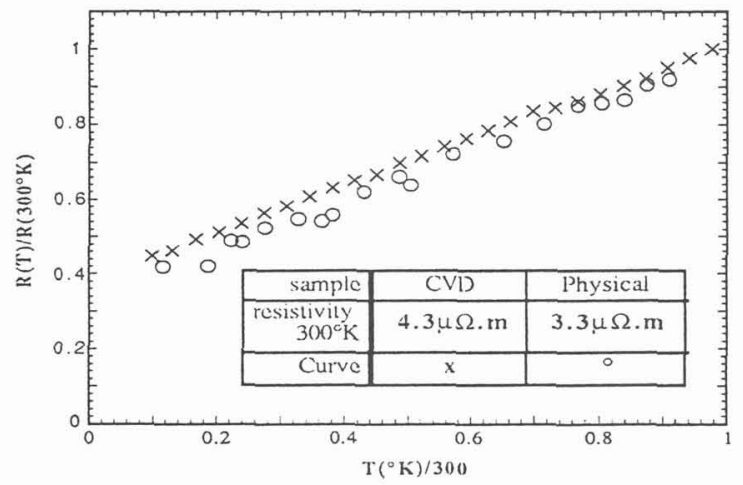

Fig $N^{\circ}$ 4: Resistance ratio versus temperature for CVD and physical evaporation copper films. 


\section{DISCUSSION:}

It is obvious that the reflectivity does not follow the same evolution as for an ideal layer by layer growing copper film. This behavior could be attributed to a different chemical composition of the surface film since we have shown by ion etching that the carbon is on top of the copper[1]. We have calculated the effect on the reflectivity of a carbon layer on top of copper. It shows that to get a decrease from $80 \%$ to $20 \%$ of the reflectivity, a $60 \mathrm{~nm}$ thick carbon film is needed. Such a thick layer for Auger spectroscopy should screen totally the copper transition. From the electrical measurements, we can also deduce that the level of contamination inside the CVD film is not high. The metallic behavior and the value of the resistivity for such film is similar to pure copper film. To explain this drastic difference in the reflectivity, we have to take into account other phenomena. It is known that the reflectivity is modified by the roughness of the surface. In the Davis theory [6], an exponential factor involving the roughness root mean square (RRMS) over the wavelenght induces a drop of the reflectivity. For a $670 \mathrm{~nm}$ wavelenght light, a $60 \mathrm{~nm}$ RRMS leads to a decrease of the reflectivity by a factor 3.5. Lecohier and co-workers [7]15] have shown that for CVD copper deposited on $\mathrm{SiO}_{2}$ the seeding of the surface by platinum influences the slop of the reflectivity in the first stages of the deposition process. A dip in the reflectivity is observed which is more pronounced when the density of nucleation sites is low. On our reflectivity curves, the same dip is observed at $375^{\circ} \mathrm{C}$, meaning that the growth involves the formation of nucleus on the surface sample. This formation is confirmed by the behavior of the Auger spectra (Fig. $\mathrm{N}^{\circ}$ 2). The coexistence of copper and silicon transitions at the beginning of the deposition process and during the increase of the reflectivity can be due to the growing of copper nucleus screening partially the silicon surface. The silicon contribution on Auger spectrum b) for a value of the reflectivity where the thickness of the equivalent film is higher than the Auger electron escape depth is another proof that using this deposition condition copper does not grow layer by layer. The MEB picture shows that the copper deposit surface is not flat due to crystallites. Due to the roughness, the maximum of the reflectivity does reach the expected value and since the chemical composition does not change a lot with the temperature, it can be deduced that increasing the deposition temperature leads to an increase in surface roughness of the film. 
From Auger spectroscopy, one can deduce that when the reflectivity reaches the maximum, the film covers the entire substrate surface. Assuming that, after the maximum, the decrease of the reflectivity can be attributed to a change of the morphology, we can quantify the evolution of the surface roughnesses using the Davis theory. Figure $N^{\circ} 5$ gives the value of RRMS as a function of the film thickness.

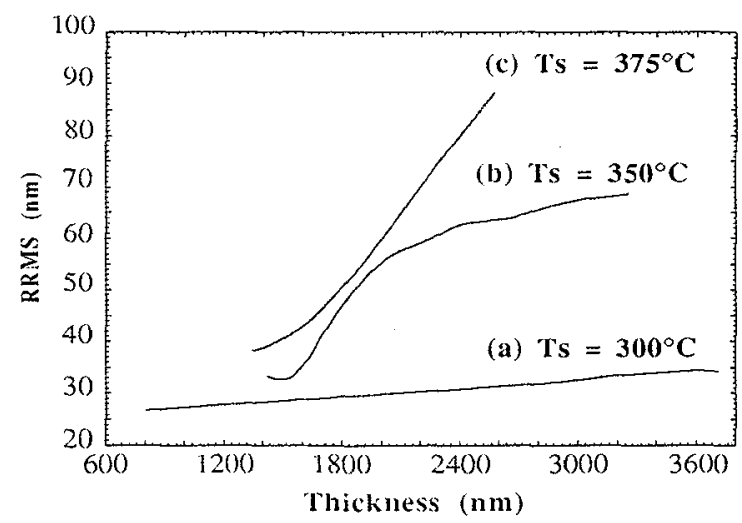

Fig N'5: Roughness root mean square of CVD copper films grown at different temperatures.

The thickness scale is deduced from the thickness measurements assuming a constant growth speed over the time of the run. In this assumption the growth rates are $1.5 \mathrm{~nm} / \mathrm{mn}$ at $300^{\circ} \mathrm{C}, 2.2 \mathrm{~nm} / \mathrm{mn}$ at $350^{\circ} \mathrm{C}$ and $3.5 \mathrm{~nm} / \mathrm{mn}$ at $375^{\circ} \mathrm{C}$. Increasing the deposition temperature leads to a drastic evolution of the roughness. At $375^{\circ} \mathrm{C}$ the deposit gets rougher than at $300^{\circ} \mathrm{C}$ where the RRMS stays below the RRMS value for higher temperature just after the maximum. At this point it is interesting to notice that Lecohier and coworkers [7][5] have shown that when the maximum of the reflectivity is reached, the resistance of the film drops. The Auger spectrum shows that the completion of the deposit is also obtained when the reflectivity reaches the maximum. The fact that the decrease of the reflectivity occurss after the completion of the deposit could be attributed to surface morphology changes due to the relaxation of lateral interactions in the film.

From the Auger data presented above, the silicon transition does not exhibit the characteristic signature of copper silicide and disappears when the film gets thick. CVD copper does not react with silicon. This behavior can be explained by the formation of a complex interface formed at the first stages of the deposition. Since silicon oxide and carbon are detected by Auger 
at the interface (spectrum a)), they could stabilize the silicon surface and prevent the reaction with copper. Experiment shows that if the physical evaporated copper film is codeposited with carbon on clean (100) silicon, the temperature of silicide formation is higher $\left(450^{\circ} \mathrm{C}\right)$ than without carbon.

\section{CONCLUSION:}

It is very important to be able to characterize a deposit during a CVD process. We have shown that the reflectivity is a simple measurement that gives information on the formation of a CVD copper film on silicon. From this measurement coupled with Auger spectroscopy, the evolution of both the morphology and the composition of the film can be deduced. From the reflectivity, the evolution of RRMS of the film can be evaluated for different deposition temperatures and the formation of the interface can be followed to explain its effect in blocking the reaction between copper and silicon.

\section{REFERENCES:}

[1] Dallaporta H., Hammadi Z., Pierrisnard R. and Cros A., "Chemical vapor deposition of copper for microelectronic devices based on silicon" ed. Vol. 1, p 889 (Les Editions de Physique: Glasgow, 1991).

[2] Hammadi Z L.B. Dallaporta H, Applied Physics Letters(1993)

[3] Daugy E., Mathiez P., Salvan F. and Layet J.M., Surf. Sci. 154 (1985) 267.

[4] Lecohier B. and van den Bergh H., Appl. Surf. Sci. 43 (1989) 61.

[5] Lecohier B., Philippoz J.M., Calpini B., Stumm T. and Bergh H.v.d., Journal de Physique II 1 (1991) 279.

[6] Davis H., Proc. Inst. Elec. Engrs. 101 (1954) 209.

[7] Lecohier B., Philippoz J.-M. and van den Bergh H., Journal of Vacuum Science Technology B 10 (1992) 262. 